\title{
Trykkammer kan tilhele sår og redusere plager etter stråling
}

Pasienter med diabetiske fotsår og stråleskader , spesielt i hode- og halsregionen, kan bli bedre med behandling i trykkammer , såkalt elektiv hyperbar oksygenbehandling.

\section{Forfattere}

\section{Anne Grøttå}

Intensivsykepleier

Hyperbarmedisinsk seksjon, Yrkesmedisinsk avdeling, Haukeland universitetssjukehus

\section{Grete Kalleklev Velure}

Seksjonsleder

Hyperbarmedisinsk seksjon, Yrkesmedisinsk avdeling, Haukeland universitetssjukehus

\section{Nøkkelord}

\begin{tabular}{|l|l|l|l|l}
\hline Diabetes Hyperbar oksygenbehandling Stråleskade Bløtvevsinfeksjoner & Trykkammer
\end{tabular}

Sykepleien 2018 106(74030)(e-74030)

DOI: https://doi.org/10.4220/Sykepleiens.2018.74030

\section{HOVEDBUDSKAP}

Ved hyperbar oksygenbehandling blir pasienter med ulike sykdomstilstander behandlet med 100 prosent oksygen under forhøyet omgivelsestrykk i trykkammer. Kombinasjonen av høy oksygenkonsentrasjon og høyt omgivelsestrykk gjør at store mengder oksygen blir tatt opp i blodet. Økt oksygenmengde stimulerer til dannelse av nye blodkar i oksygenfattig vev. Stråleskader etter kreft i hode- og halsområdet, stråleskadet tarm og blære og diabetiske fotsår er tilstander som kan ha effekt av denne behandlingen. 
Nasjonal behandlingstjeneste for elektiv hyperbar oksygenbehandling (HBO) er lokalisert til Haukeland universitetssjukehus, Yrkesmedisinsk avdeling. Her er det 6 enmannstrykkammer der 24 elektive pasienter behandles daglig.

Behandlingen er en poliklinisk seriebehandling der pasientene bor på sykehotellet, eventuelt hjemme, dersom de kommer fra nærområdet. Prinsippet om likt helsetjenestetilbud til alle følges, og pasientene kommer fra hele landet (1).

Den elektive HBO-behandlingen gjennomføres i enmannstrykkammer. Pasienten blir trykksatt med 100 prosent oksygen til 2,40 bar, som tilsvarer 14 meter under vann. Daglig behandling er på totalt 90 minutter. Luftpustepauser og dekompresjon av trykkammeret kommer i tillegg, slik at hver behandling varer i underkant av 2 timer.

\section{三 «Pasienten blir trykksatt med 100 prosent oksygen til 2,40 bar, som tilsvarer 14 meter under vann.»}

En behandlingsperiode er på to til seks uker.

Diagnosen avgjør behandlingsforløpet. Effekten av behandlingen kan først ventes seks til åtte uker etter avsluttet behandling $(2,3)$.

\section{Hvorfor HBO-behandling?}

I stråleskadet vev og ved diabetiske fotsår er mikrosirkulasjonen redusert, og det oppstår hypoksi i affiserte områder. Ved HBO-behandling dannes det nye blodårer i dårlig sirkulert vev, slik at oksygen og næringsstoffer tilføres området.

Høy oksygenkonsentrasjon hjelper de hvite blodlegemene til å drepe bakterier. Formålet er å bedre sirkulasjonen i dårlig sirkulert vev, slik at skadeområdet heles og pasientens plager reduseres (2, 3). 


\section{FORKLARINGER PÅ FAGBEGREPER}

Hypoksi: generell oksygenmangel, en tilstand med for lav oksygentilførsel til kroppens vev

Osteoradionekrose: stråleskade av beinsubstans, vanligvis som senskade etter strålebehandling

Xerosotomi: munntørrhet

Dysfagi: svelgebesvær, problemer med å få ned maten

Dysartri: utydelig tale eller vansker med å uttale ord på grunn av sykdom, skade i taleorganet eller nervene som kontrollerer dette

Proktitt: betennelse i endetarmen

Stråleproktitt: betennelse i endetarmen som senskade etter strålebehandling

Cystitt: urinblærebetennelse, smertefulle vannlatinger, noen ganger også blod i urinen

Strålecystitt: stråleskader i blæren

Osteomyelitt: betennelse i bein og beinmarg

Pneumothorax: luft i pleurahulen, som forekommer når luft slipper inn mellom den delen av pleura (brysthinnen) som kler lungenes overflate (pleura visceralis), og den delen som kler brystkassens innside (pleura parietalis)

Ørebeinsknokler: hammer, ambolt, stigbøyle. Kalles også ørebein, høreknokler

Bleomycinterapi: cellegiftbehandling av antibiotikatypen

Paracentese: punksjon av veggen i et hulrom for å drenere $ø$ kt mengde væske

Kilder: Store medisinske leksikon, Tidsskrift for Den no rske legeforening og Norsk medisinsk ordbok (1994)

\section{Kunnskap om tilbudet}


Tilbakemeldinger fra våre pasienter tyder på at det finnes for lite kunnskap om behandlingstilbudet, både innen primær- og spesialisthelsetjenesten. De mener vi må jobbe mer aktivt utadrettet for å informere om tilbudet. Denne artikkelen er et bidrag til å spre mer kunnskap om elektiv HBO-behandling innen sykepleietjenesten.

Vi ønsker at tilbudet skal være kjent for aktuelle brukere av behandlingstilbudet samt sykepleiere, leger og tannleger som behandler pasienter med godkjente behandlingsdiagnoser. Formålet er at pasientene skal få en bedre livskvalitet etter gjennomført behandling ved seksjonen vår.

\section{Indikasjoner}

De følgende punktene er indikasjoner for HBObehandling:

- Stråleskade etter kreftbehandling i hode- og halsregionen i form av osteoradionekrose, xerosotomi, dysfagi, dysartri samt før og etter planlagt kirurgi eller tannbehandling i bestrålt område $(2,3)$. Ved tannbehandling eller kirurgi i bestrålt område skal det gjennomføres henholdsvis 20 , eventuelt 30 , preoperative samt 10 postoperative HBO-behandlinger. Diagnose er avgjørende for antall preoperative behandlinger.

- Stråleskader i bekkenregionen med stråleproktitt, strålecystitt samt ved osteoradionekrose i bekkenringen $(2,3)$.

- Kronisk osteomyelitt, der adekvat behandling (best practice) ikke har ført frem og mikroben er verifisert ut fra beinbiopsi. HBO-behandlingen vil være tilleggsbehandling til kirurgi og antibiotikabehandling $(2,3)$.

- Kroniske hypoksiske sår, der makrosirkulasjonen er vel bevart, som ved diabetiske fotsår $(2,3)$. 
Formålet med behandlingen er å bedre

blodgjennomstrømmingen i dårlig sirkulert vev, noe

som aktivt motvirkes av røyking på grunn av

nikotinets karkontraherende effekt. Pasienter som skal

til HBO-behandling, må derfor slutte å røyke eller

snuse tre uker før behandlingen starter $(2,3)$.

\section{三 «Formålet med behandlingen er å bedre blodgjennomstrømmingen $\mathrm{i}$ dårlig sirkulert vev.»}

\section{Kontraindikasjoner}

Det følgende er kontraindikasjoner for HBO-

behandling:

- Gravide, brukere av Antabus og personer med alvorlig hjertesvikt, nylig gjennomgått lungebetennelse, kronisk lungesykdom, pneumothorax, kunstige ørebeinknokler, bleomycinterapi i sykehistorien og aktiv kreftsykdom skal ikke ha HBO-behandling $(2,3)$.

\section{HBO-pasientens symptomer}

Pasienter som har hatt stråling mot hals eller kjeve, er i stor grad plaget av munntørrhet. De kan derfor ha store svelgevansker, og det kan være problematisk for dem å spise vanlig mat. En del er avhengig av sondeernæring, eller de lever på ernæringsdrikker.

Vi har mange pasienter med stråleskader i mage-, tarm- og bekkenregionen med symptomer som i stor grad er hemmende for dem i det daglige. Noen kan ha transfusjonskrevende blødninger - andre er svært plaget av hyppig vannlating eller tarmtømming, og må av den grunn holde seg i nærheten av et toalett.

I tillegg er smerter et problem for mange. Pasientene har gjerne vært gjennom ulike behandlinger for å redusere plagene uten å lykkes og kommer til oss med håp om å få hjelp. 
Smerter er en vesentlig faktor for pasienter med mikrofrakturer. Mikrofrakturer kan ses i bekkenet etter stråling relatert til kreft i tarmen eller blæren og ved gynekologiske tilstander.

Hos pasienter med diabetiske fotsår gjennomføres regelmessige sårskift. Hos disse pasientene kan man visuelt følge effekten av behandlingen. Noen sår tilheler i løpet av behandlingsperioden, men ikke alle $(4,5)$.

\section{Forberedelse til behandling}

I forkant av behandlingen får pasienten tilsendt mye informasjon, og alle pasienter som skal til førstegangsbehandling, er alltid på informasjonsmøte før behandlingsstart. Vi informerer om sikkerhetstiltak relatert til risikoen ved behandling med 100 prosent oksygen samt aktuelle bivirkninger som kan oppstå.

Pasientene får også diverse praktisk informasjon. Informasjonen kan også finnes på seksjonens hjemmes ide, som vi henviser til i informasjonsmateriellet. Mye av informasjonen som gis på informasjonsmøtet, blir gjentatt av en sykepleier før oppstarten av første behandling.

\section{Sikkerhetstiltak}

Under behandlingen ligger pasienten på en båre i trykkammeret. Kammeret består av akrylglass og metall. På grunn av store trykkforskjeller forsegles kammeret under behandlingen. Kammeret fylles med 100 prosent oksygen, noe som utgjør en stor sikkerhetsrisiko. Derfor er det påkrevd med strenge sikkerhetskrav $(3,6)$.

I trykkammeranlegget er det absolutt forbudt å medbringe fyrstikker, lightere og e-sigaretter. Avdelingens bomullstøy benyttes under behandlingen.

\section{三 «Det er strenge regler for hva som er tillatt $i$ kammeret.»}


Brann i kammeret er forbundet med stor fare og er noe vi frykter og aktivt arbeider med å forebygge. For å unngå statisk elektrisitet får pasienten på seg et jordingsarmbånd under behandlingen.

Det er strenge regler for hva som er tillatt i kammeret. For å sikre en så trygg behandling som mulig gjennomgår vi en sjekkliste med pasienten før hver behandling. Eksempelvis er fettholdige produkter kontraindisert, da fett kan være selvantennelig ved høy oksygenkonsentrasjon under forhøyet omgivelsestrykk $(2,6)$.

\section{Mulige bivirkninger}

En kjent bivirkning med HBO-behandling er problemer med å utlikne trykket under trykksettingen. Da kan pasienten få sterke smerter i ørene $(2,3,6,7)$. En stor andel av våre pasienter opplever i større eller mindre grad smerter i ørene ved trykksetting.

Trykksettingen er en viktig fase i behandlingen. Sykepleieren må være svært oppmerksom overfor pasienten. Smerter kan oppstå plutselig, selv om pasienten ikke har opplevd smerter tidligere. Sykepleieren kan regulere tempoet på trykksettingen og sette i verk tiltak for å lette pasientens smerter, slik at han klarer å utlikne trykket, og trykksettingen kan fortsette.

Noen pasienter må i perioder benytte slimhinneavsvellende medikamenter i form av nesespray eller tabletter for å klare å utjevne trykket. Enkelte pasienter må få utført paracentese for å klare å gjennomføre behandlingen.

En sjelden, men kjent bivirkning er oksygenkramper som følge av at pasientens hjerne tilføres høykonsentrert oksygen under behandlingen. For å forebygge kramper puster pasienten luft på maske $2 \mathrm{x}$ 5 minutter i løpet av en behandling $(2,3,6)$. 
Synsendringer i form av nærsynthet er en kjent

bivirkning. Slike synsendringer er forbigående, og synet vil vanligvis gå tilbake til «normaltilstand» cirka tre måneder etter avsluttet HBO-behandling (8-10). En overvekt av våre pasienter opplever synsforandringer $\mathrm{i}$ løpet av behandlingsperioden.

Enkelte blir mer trøtte enn normalt når de gjennomgår HBO-behandling. Trøtthet er en kjent bivirkning ved dykking $(2,3,6)$.

\section{Sjeldne bieffekter}

Av de mer sjeldne «bivirkningene» kan vi nevne klaustrofobi (2, 3, 7). Behandlingen foregår i et trykkammer i form av en forseglet sylinder. For å komme ut er pasienten helt avhengig av andres hjelp. Informasjon i forkant av behandlingen og sykepleierens omsorg og nærvær er av stor betydning for hvordan pasienten takler oppholdet i trykkammeret.

\section{三 «For noen er det nyttig å vite at vi kan ta dem opp og ut av kammeret i løpet av vel ett minutt.»}

Disse faktorene er ikke alltid nok; noen har behov for

et beroligende medikament i forkant for å klare å gjennomføre behandlingen. Enkelte bruker medikamentet noen få dager, mens andre har behov for denne formen for «premedikasjon» i hele behandlingsforløpet. For noen er det også nyttig å vite at vi kan ta dem opp og ut av kammeret i løpet av vel ett minutt.

Over hvert kammer er det en TV-skjerm, slik at pasienten kan se film eller TV under behandlingen. Enkelte foretrekker imidlertid lydbok. Det er viktig at pasienten har noe engasjerende å fokusere på. Da går tiden raskere, og for mange blir den klaustrofobiske følelsen mindre dominerende. 
Noen kunne nok tenkt seg å sove gjennom

behandlingen, men det får de ikke lov til. Under søvn

puster de ikke godt nok, og de er vanskeligere å observere.

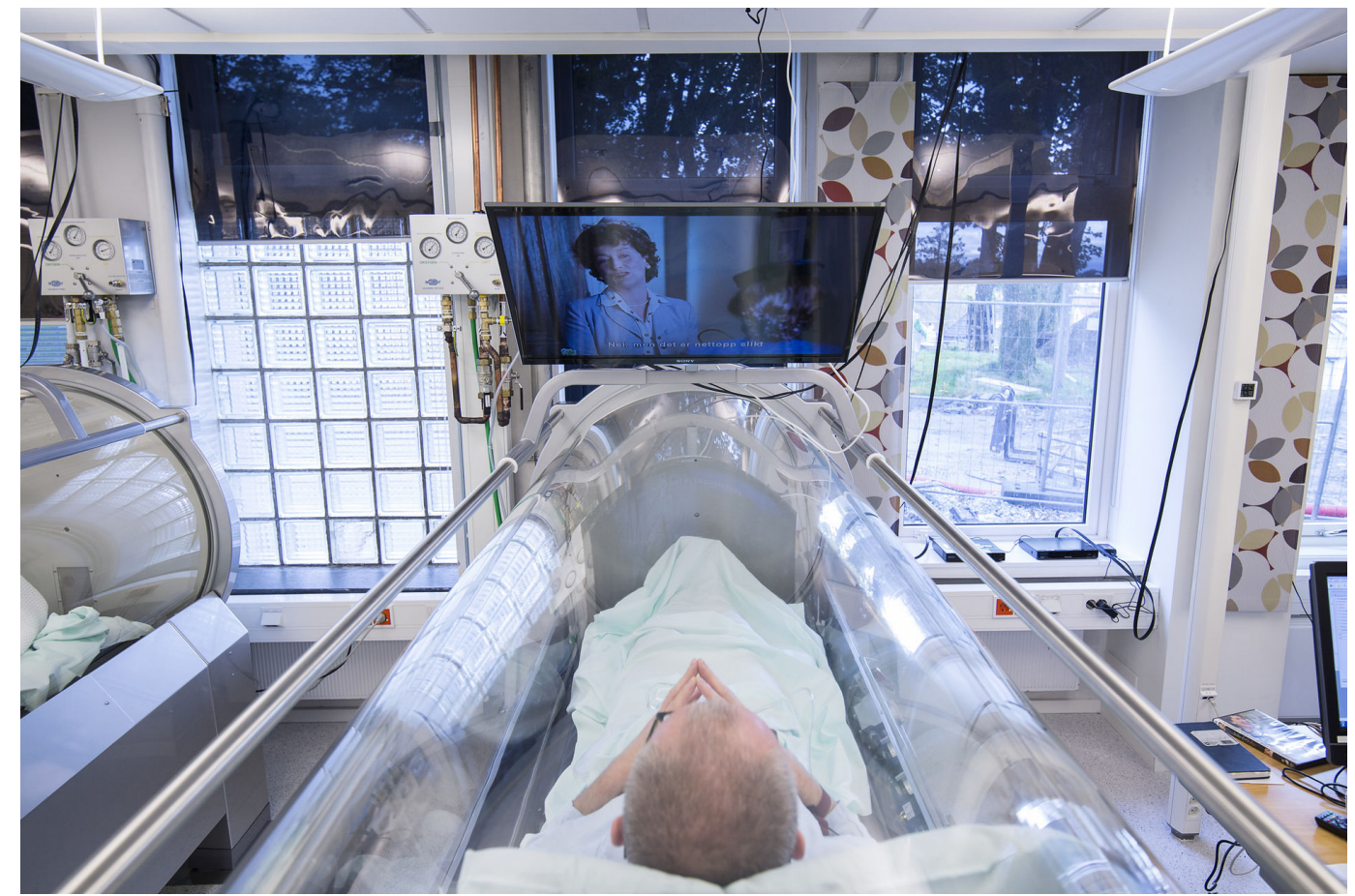

SER PÅ TV: Det er viktig at den som får behandling i trykkammer, har noe engasjerende å gjøre for å få tiden til å gå. (Illustrasjonsfoto: Katrine Sunde / Haukeland universitetssjukehus)

\section{Effekt av behandlingen}

Som nevnt kan man ikke forvente noen effekt av behandlingen før seks til åtte uker etter avsluttet behandling (2). Likevel hevder enkelte pasienter at de er blitt bedre i løpet av behandlingsperioden.

HBO-behandling er omdiskutert, men det er dokumentert gjennom randomiserte studier at den kan ha effekt på diabetiske fotsår $(4,5)$ og på stråleskader i hode- og halsregionen $(5,11)$. Det er mer omdiskutert hvorvidt behandlingen har effekt på stråleskader i mage-, tarm- og bekkenregionen, da forskningsresultatene peker i litt ulike retninger. Mange av studiene er små og retrospektive med risiko for skjevhet (5).

\section{Forskning}


Det er viktig med dokumentasjon av

behandlingseffekten. Det er et lite miljø som driver

elektiv HBO-behandling, og vi må gjerne jobbe

sammen nasjonalt og internasjonalt når vi forsker. Vår seksjon arbeider aktivt med forskning.

Vi er for tiden blant annet med i en felles nordisk multisenterstudie som gjennomfører en kontrollert, randomisert studie relatert til effekten av HBObehandling ved strålecystitt. Resultatene av denne studien vil gi oppdatert kunnskap på fagfeltet. I tillegg til pågående studier er vi i planleggingsfasen av nye studier, der behandlingseffekten er en del av det vi skal studere.

\section{Mer informasjon}

Sykepleierne ved Hyperbarmedisinsk seksjon laget for en tid tilbake en video. Her kan du se hvordan behandlingen foregår:

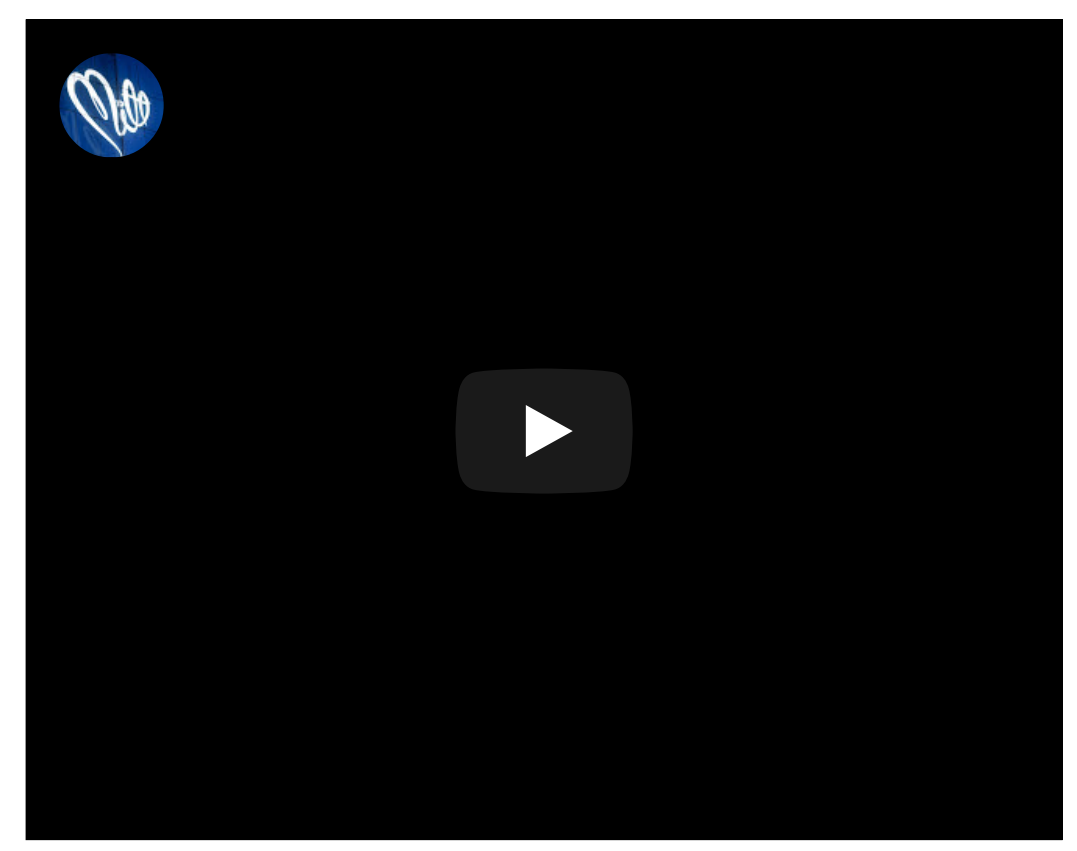

Kilde: Haukeland universitetssjukehus

Videoen er publisert på YouTube og finnes også på sek sjonens hjemmeside, der det er mer informasjon om behandlingstilbudet.

\section{Referanser}


1. Lov 2. juli 1999 nr. 63 om pasient- og brukerrettigheter (pasient og brukerrettighetsloven). Tilgjengelig fra: https://lovdata.no/dokument/NL/lov/1 999-07-02-63 (nedlastet 02.11.2018).

2. Helse Bergen, Haukeland universitetssjukehus.Hyperbar oksygenbehandling, planlagt [internett]. Bergen: Helse Bergen; 2018 [oppdatert 05.04.2018, sitert 14.03.2018]. Tilgjengelig fra: https://helse-bergen.no/behandlinger/hyperbar-oks ygenbehandling-planlagt

3. Helse Bergen, Haukeland universitetssjukehus. Nasjonal behandlingstjeneste for elektiv hyperbar oksygenbehandling [internett]. Bergen: Helse Bergen; 2018 [sitert 14.03.2018]. Tilgjengelig fra: https://helsebergen.no/avdelinger/yrkesmedisinsk-avdeling/nasjona l-behandlingsteneste-for-elektiv-hyperbar-oksygenbeh andling.

4. Löndahl M, Katzman P, Nilsson A, Hammarlund C. Hyperbaric oxygen therapy facilitates healing of chronic foot ulcers in patients with diabetes. Diabetes Care. 2010;33(5):998-1003.

5. Lauvrak V, Frønsdal KB, Ormstad SSO, Vaagbø G, Fure B. Effekt av hyperbar oksygenbehandling ved senskader etter stråleterapi eller diabetiske fotsår. Oslo: Nasjonalt kunnskapssenter for helsetjenesten; 2015. Rapport 4/2015.

6. Ørnhagen H. Dykerimedicin og hyperbar fysiologi. Lund: Studentlitteratur; 2011.

7. Larson-Lohr V, Norvell HC. Hyperbaric nursing. Flagstaff, Arizona: Best Publishing Company; 2002. 
8. Evanger K, Haugen OH, Irgens Å, Aanderud L, Thorsen E. Ocular refractive changes in patients receiving hyperbaric oxygen administered by oronasal mask or hood. Acta Ophthalmol Scand. 2004;82(4):449-53.

9. Evanger K, Haugen OH, Aanderud L, Thorsen E, Pierscionek BK. Hypermetropia-succeeded myopia after hyperbaric oxygen therapy. Optometry and Vision Science. 2006;83(3):195-8.

10. Evanger K, Vaagbø G, Thorsen E, Haugen OH. Phakic and pseudophakic eyes in patients during hyperbaric oxygen therapy optom. Vis Sci.

2011;88(6):691-6.

11. Svalestad J, Thorsen E, Vaagbø G, Hellem S. Effect of hyperbaric oxygen treatment on oxygen tension and vascular capacity in irradiated skin and mucosa. Int J Oral Maxillofac Surg. 2014;43(1):10712. 